\title{
IDENTIDAD E INCLUSIÓN. LOS \\ CONJUNTOS DE VIVIENDAS REALIZADOS POR EL ARQUITECTO CHILENO LUCIANO KULCZEWSKI (1922-1956)
}

Identidade e inclusão. Os conjuntos

habitacionais do arquiteto chileno Luciano

Kulczewski (1922-1956)

Identity and inclusion. The housing complexes

made by the Chilean architect Luciano

Kulczewski (1922-1956)

Este artículo es el resultado de una investigación FON$D E C Y T$, proyecto folio $\mathrm{n}^{\circ}$ 11180495, se agradece el financiamiento. Se reconoce también la colaboración de Daniel González Erices (Universidad Adolfo lbáñez) y Raúl Pacheco Aravena (Universidad de Chile).

Estudio de

fachadas, conjunto

habitacional no

identificado. Fuente:

identificado. Fuente:

Ortega, 0. (1074).

Luciano Kulczewski

García ". AUCA 26

45-48.

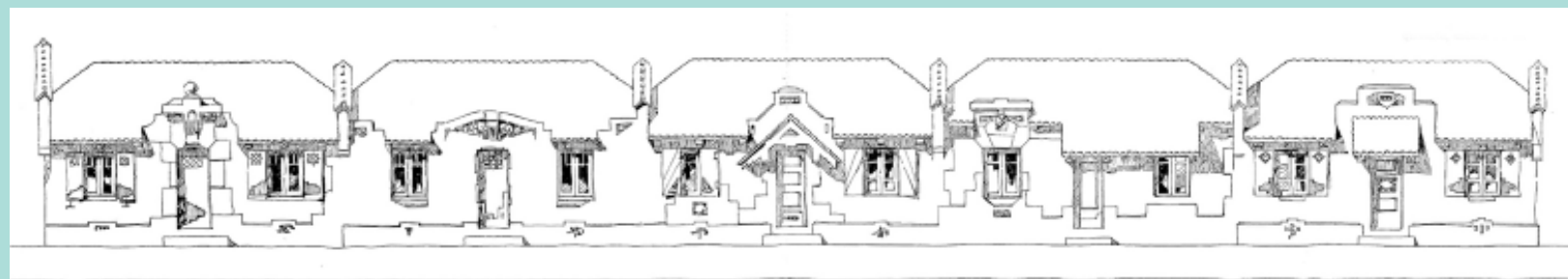




\section{RESUMEN}

Luciano Kulczewski fue un profesional que cumplió un rol clave y distintivo en la primera mitad del siglo XX, período que se considera crucial para el desarrollo de la arquitectura chilena ya que es el momento en que se produce el advenimiento de la modernidad en el país. Una de las ilustraciones más elocuentes a este respecto es el corpus constituido por más de una docena de conjuntos habitacionales destinados a los estratos socioeconómicos medios y populares. Hoy reconocemos en estas soluciones no solo el hecho de que se hallen en sincronía con la trama de procesos sociales, políticos, culturales y económicos que determinaron los comienzos del siglo pasado en Chile, sino que tienen también, entre sus méritos más destacables, el haber sido concebidas en términos de lo que hoy entenderíamos por "inclusión". El presente artículo busca indagar en estos parámetros, que abarcan desde las propuestas urbanas -que se aproximaban a la ciudad en términos "inclusivos", en cuanto renunciaban a relegar estas propuestas habitacionales hacia las periferias metropolitanas-, hasta cuestiones más particulares, como era el manejo estilístico de las viviendas a guisa de herramienta puesta al servicio de causas identitarias, con el fin de lograr la integración del usuario con su entorno.

Palabras Clave: Ciudades jardín, conjuntos habitacionales, identidad arquitectónica, inclusión social, viviendas en cooperativa

\section{RESUMO}

Luciano Kulczewski foi um profissional que cumpriu um papel fundamental e distintivo na primeira metade do século $X X$, período considerado crucial para o desenvolvimento da arquitetura chilena por ser o momento em que ocorre o advento da modernidade no país. Uma das ilustrações mais eloquentes a esse respeito é o corpus formado por mais de uma dúzia de conjuntos habitacionais voltados para as camadas socioeconômicas médias e populares. Hoje reconhecemos nessas soluções não apenas o fato de que estão em sintonia com a teia de processos sociais, políticos, culturais e econômicos que marcaram os primórdios do século passado no Chile, mas também, entre seus méritos mais notáveis, o fato de terem sido concebidas em termos do que entenderíamos hoje por "inclusão". Este artigo busca investigar esses parâmetros, que vão desde as propostas urbanas, que abordaram a cidade em termos "inclusivos" - na medida em que desistiram de relegar essas propostas habitacionais às periferias metropolitanas -, até questões mais particulares, como a gestão estilística das moradias como ferramenta ao serviço das causas identitárias, no intuito de conseguir a integração do usuário com o seu ambiente.

Palavras-Chave: Cidades-jardim, conjuntos habitacionais, identidade arquitetônica, inclusão social, habitação cooperativa

\section{ABSTRACT}

Luciano Kulczewski was a professional who played a key and distinctive role in the first half of the 20th century, a period considered as crucial for the development of Chilean architecture, since it is the moment that brought the advent of modernity to the country. One of the most eloquent illustrations in this regard is the corpus, that collects more than a dozen housing complexes aimed for the middle and the working classes. Today, we recognize in these solutions not just the fact that they are in sync with the web of social, political, cultural, and economic processes that characterized the beginnings of the past century in Chile, but that they also have, among their most notable merits, having been conceived in terms of what we would understand today by "inclusion". This article seeks to investigate these parameters, which range from urban proposals - that approached the city in "inclusive" terms - inasmuch as they did not push for these housing proposals to be in the metropolitan peripheries - to more particular issues, such as the stylistic management of homes as a tool to serve identity causes, in order to achieve the integration of the user with their environment.

Keywords: Garden cities, housing complexes, architectural identity, social inclusion, cooperative housing 


\section{INTRODUCCIÓN}

1 Sobre clase media e identidad, véase: Méndez y Bazoret (2012).

2 Para un análisis reciente de este fenómeno, véase Duk y Murillo (2016), además de Afacan, Y. y Afacan S. (2011).

3 Un cité es un grupo de casas que comparten un patio interior en forma de pasillo.
A principios del siglo $X X$, cuando se consolidaban los procesos de modernización en Chile, destacaba en el ámbito de la arquitectura la figura de Luciano Kulczewski García (1 896-1972). Su obra, de forma diáfana, revela los retos que significó para la sociedad y el estado chileno este transitar. Sus propuestas, tanto arquitectónicas como urbanas, manifiestan no solo un esfuerzo de renovación formal y plástica, sino que también la intención de hacerse cargo del proyecto ético y social que acarreaban las vanguardias. Con esta disposición, la empoderada clase media afloraba como un actor relevante, jugando un rol clave frente a los desafíos que debería atravesar el país con el devenir de la centuria. En ese marco, entre una rancia oligarquía, que hasta entonces había dominado el ambiente político, y las luchas emprendidas por el proletariado, los estratos intermedios sintieron la necesidad de construir un espacio identitario que les fuera propio ${ }^{1}$. En este sentido, y solo desde el aspecto mediático, su corpus productivo ha logrado ser individualizado por la comunidad, por ende, reconocido como parte del imaginario urbano nacional (Harris, 2016).

Con la intención de precisar las estrategias que sustentan esta afirmación, los argumentos recogidos en el presente artículo centrarán su mirada en los conjuntos habitacionales que, dirigidos a las extracciones medias y populares, fueron llevados a cabo por Kulczewski. La idoneidad de estos ejemplos es sincrónica con la renovación que implicó la desestabilización de los procesos sociales y culturales que el país venía arrastrando desde el siglo XIX, pero además se trata de propuestas que, vistas desde la actualidad, fueron resueltas bajo lo que hoy podríamos caracterizar como "inclusivas"2.

Las primeras indagaciones realizadas para la investigación que aquí se expone se iniciaron con el estudio de fuentes historiográficas que abordan las creaciones a este respecto más conocidas del Kulczewski, a saber, las poblaciones de calle Catedral (1923), de calle Madrid (1925), para Suboficiales de Caballería (1926-1928), población Los Castaños (1927-1930), población Comunidad Keller (ca. 1930) y el conjunto Virginia Opazo ( 194 | - 1944). Cabe decir que tales textos nunca eran acompañados de planimetrías originales, por lo que las pesquisas que se prolongaron por más de dos años en los archivos técnicos de las Direcciones de Obras comunales (DOM), del Ministerio de Obras Públicas y de Aguas Andinas (donde la búsqueda fue más fructífera). Los planos de instalaciones allí obtenidos fueron las fuentes, que, junto con el trabajo en terreno, permitieron llevar a cabo planimetrías digitales, parte de las cuales se han incorporado en este artículo.

Producto de este paciente escrutinio es que salieron a la luz una serie de obras de Kulczewski, todavía inéditas, que duplican el corpus conocido de sus realizaciones, entre ellas, los conjuntos de viviendas de calle Santo Domingo (1922), de calle Esperanza (1923), Cité $^{3}$ Esperanza (1923-1924), para Suboficiales del Regimiento 
Tabla 1.

Conjuntos residenciales llevados a cabo por Luciano Kulczewski.

Fuente: Elaboración del autor.
Tacna (1927-1928), Cooperativa de Empleados Emilio Delporte (1929), Caja Nacional de Ahorros (1930), General Saavedra (19441945), calle Pintor Cicarelli (1945-1952), y por último, el conjunto de la comuna de Vitacura (1956) [Tabla I].

Por otro lado, a estas quince creaciones, que comparten el hecho de haber sido todas elaboradas en la capital del país, se suman los conjuntos levantados en provincias: los edificios colectivos para obreros de Arica, Iquique, Antofagasta y Tocopilla (1939-1940), y el conjunto de viviendas de Isla Teja (1939-1940), en Valdivia. Estas obras serán abordadas más soslayadamente en el entendido de que el rol que le cupo a Kulczewski en la materialización de ellas fue antes bien

\begin{tabular}{|c|c|c|c|c|c|}
\hline Conjunto & Años & Mandante & $\begin{array}{l}\mathrm{N}^{\circ} \text { de } \\
\text { viviendas }\end{array}$ & Comuna & Ciudad \\
\hline Viviendas de calle Santo Domingo & 1922 & Alejandro Guttmann L. & 6 & Santiago & Santiago de Chile \\
\hline Viviendas de calle Esperanza & 1923 & Alejandro Guttmann L. & 8 & Santiago & Santiago de Chile \\
\hline Cité Esperanza & 1923-1924 & Alejandro Guttmann L. & 31 & Santiago & Santiago de Chile \\
\hline Viviendas calle Catedral & 1923 & Alejandro Guttmann L. & 6 & Santiago & Santiago de Chile \\
\hline Poblacion calle Madrid & 1925 & Alejandro Guttmann L. & 15 & Santiago & Santiago de Chile \\
\hline $\begin{array}{l}\text { Poblacion Suboficiales de la Escuela de } \\
\text { Caballería }\end{array}$ & 1926-1928 & Caja de la Defensa Nacional & 113 & Ñuñoa & Santiago de Chile \\
\hline $\begin{array}{l}\text { Población para Suboficiales del } \\
\text { Regimiento Tacna }\end{array}$ & $1927-1928$ & Ejército de Chile & 26 & Santiago & Santiago de Chile \\
\hline Poblacion Los Castaños & $1927-1930$ & $\begin{array}{l}\text { Caja de Asistencia, Previsión } \\
\text { y Bienestar de las Policías }\end{array}$ & 85 & Independencia & Santiago de Chile \\
\hline $\begin{array}{l}\text { Población Cooperativa de Empleados } \\
\text { Emilio Delporte }\end{array}$ & 1929 & $\begin{array}{l}\text { Cooperativa Arturo Prat de } \\
\text { Empleados Emilio Delporte }\end{array}$ & 39 & Providencia & Santiago de Chile \\
\hline Población Comunidad Kellerw & ca. 1930 & $\begin{array}{l}\text { Emilio Keller Portales y } \\
\text { Demófila Portales }\end{array}$ & 28 & Providencia & Santiago de Chile \\
\hline Población Caja Nacional de Ahorros & 1930 & Caja Nacional de Ahorros & 9 & Providencia & Santiago de Chile \\
\hline $\begin{array}{l}\text { Edificios Colectivos para Obreros de } \\
\text { Arica }\end{array}$ & $1938-1940$ & $\begin{array}{l}\text { Caja del Seguro Obrero } \\
\text { Obligatorio }\end{array}$ & 110 & Arica & Arica \\
\hline $\begin{array}{l}\text { Edificios Colectivos para Obreros de } \\
\text { Iquique }\end{array}$ & $1938-1940$ & $\begin{array}{l}\text { Caja del Seguro Obrero } \\
\text { Obligatorio }\end{array}$ & 80 & Iquique & Iquique \\
\hline $\begin{array}{l}\text { Edificios Colectivos para Obreros de } \\
\text { Tocopilla }\end{array}$ & $1938-1940$ & $\begin{array}{l}\text { Caja del Seguro Obrero } \\
\text { Obligatorio }\end{array}$ & 110 & Tocopilla & Tocopilla \\
\hline $\begin{array}{l}\text { Edificios Colectivos para Obreros de } \\
\text { Antofagasta }\end{array}$ & $1938-1940$ & $\begin{array}{l}\text { Caja del Seguro Obrero } \\
\text { Obligatorio }\end{array}$ & 110 & Antofagasta & Antofagasta \\
\hline Conjunto de viviendas de Isla Teja & $1938-1940$ & $\begin{array}{l}\text { Caja del Seguro Obrero } \\
\text { Obligatorio }\end{array}$ & 56 & Valdivia & Valdivia \\
\hline Conjunto Virginia Opazo & $1941-1944$ & $\begin{array}{l}\text { Caja de Previsión de las } \\
\text { Fuerzas Armadas }\end{array}$ & 33 & Santiago & Santiago de Chile \\
\hline Población General Saavedra & 1944-1945 & Lucía Yánquez Cerda & 8 & Independencia & Santiago de Chile \\
\hline Conjunto Calle Pintor Cicarelli & 1945-1952 & Diversos Propietarios & 7 & Independencia & Santiago de Chile \\
\hline Viviendas en la Comuna de Vitacura & 1956 & $\begin{array}{l}\text { Sociedad Cooperativa de } \\
\text { Viviendas Metrópoli Ltda }\end{array}$ & 70 & Vitacura & Santiago de Chile \\
\hline
\end{tabular}




\section{ORNAMENTO E IDENTIDAD}

AS / Vol. 39. N60 / JULIO 2021 // ISSN impresa 0716-2677 / ISSN digital 0719-6466

IDENTIDAD E INCLUSIÓN. LOS CONJUNTOS DE VIVIENDAS REALIZADOS POR EL ARQUITECTO

CHILENO LUCIANO KULCZEWSKI (1922-1956)

Ronald Harris Diez de gestor político, como director administrativo frente a la Caja del Seguro Obrero Obligatoria (Galaz-Mandakovic, 2011; Harris, 2020).

Fue pertinente, frente a las transformaciones que han sufrido estos conjuntos, buscar en las colecciones de fotografías históricas imágenes que pudieran dar cuenta de su aspecto original. De la misma manera, se indagó en revistas y prensa de la época, ya fuesen publicaciones especializadas de arquitectura $\circ$ magazines. Fruto de esa labor, se dispone ahora de una serie de obras que se encuentran en proceso de identificación y análisis. Estas fuentes también proporcionan los escasos testimonios donde escuchamos la voz en primera persona del arquitecto. Si bien, como se verá, se trata de discursos articulados desde un rol político, manifiestan indicios de su idea del quehacer de un arquitecto y su forma de concebir la ciudad.

De forma excepcional, a partir de la década de 1960, la actitud visionaria de académicos como Fernando Riquelme y Óscar Ortega, interesados en la obra de Kulczewski - a contracorriente de los rígidos dictámenes de estilo internacional imperante-, motivó la aparición de artículos y un libro monográfico (Riquelme, 1996). A estos se suman variados trabajos de investigación efectuados por sus alumnos, entre los que destaca el de Enrique Burmeister (1969), que tiene el mérito de haber realizado una extensa entrevista al arquitecto, hoy de conocimiento obligado para cualquier estudioso de su legado.

Durante la reflexión que acompañó el proceso de sistematización de la información recabada, se hizo evidente que los conjuntos habitacionales realizados por Kulczewski poseían transversalmente, entre otros valores, el haber sido concebidos bajo parámetros que hoy definiríamos como identitarios y socialmente inclusivos. El propósito de este artículo es, precisamente, visibilizar la eficacia de los procedimientos que permitieron estos logros.

Cien años atrás, la obra de Kulczewski se erigía pionera en distintos sentidos. Por aquel entonces, debido a que las principales ciudades del país se encontraban en pleno proceso de metropolización, las inquietudes de las autoridades y de los arquitectos se vinculaban, principalmente, con la idea de congeniar progreso y desarrollo - es decir, urbes inclusivas y sustentables-. De este modo, la temática de la vivienda para las clases media y obrera comenzaba por primera vez a ser encarada; cuestión que haría que los proyectos de Kulczewski se considerasen referenciales hoy por hoy. El cuidadoso manejo de la escala de sus propuestas a nivel urbano y, sobre todo, su tratamiento formal, son los elementos en los que estriba el destacado sitial ocupado por el arquitecto. En su obra, cada casa resulta individualizada por medio de la disposición de los elementos ornamentales de la fachada, favoreciendo así la identificación del usuario con su residencia; un recurso que entraría en crisis con el arribo del Movimiento Moderno. Como el propio Kulczewski expresaba: "la vivienda debe estar bien situada, de 
acuerdo con las necesidades de trabajo de sus ocupantes, debe ser bien construida, alegre, confortable y bella, no importa su costo" (Burmeister, 1969). Esta sensibilidad se tradujo, entonces, en una operación que permitió al arquitecto integrar las aparentes contradicciones que entrañarían lo plural y lo singular en el contexto de las tipologías residenciales.

El aludido manejo ornamental tenía como fin humanizar la arquitectura y favorecer el sentido de identidad. Así, sus conjuntos se configuraban, en general, a partir de una variedad acotada de viviendas tipo pero que, en lo tocante a los tratamientos formales, era ilimitada. Sin embargo, ello no suponía la pérdida de un sentido unitario, tal cual lo explicitaba el arquitecto:

... [estoy] totalmente en contra de la proletarización del hombre común. Al contrario [,] yo lo quiero levantar. Eso fue lo que me llevó [...] a hacer todas esas poblaciones con las casas distintas unas de otras, pero dentro de una semejanza común. (Burmeister, 1969)

Es justo recordar que esta operación estaba bastante extendida en su época, pero al menos, para el medio chileno, Kulczewski constituye uno de sus destacados exponentes.

Siguiendo la línea de pensamiento establecida por Palmer (1984), a partir de su interpretación del ensayo Carácter y composición, o algunas vicisitudes del vocabulario arquitectónico del siglo XIX (Rowe, 1980), pareciera reconocerse aún en el trabajo de los arquitectos de la primera mitad del siglo pasado un afán por trabajar los aspectos compositivos y formales de un edificio, al servicio de lo que los tratadistas de los siglos XVIII y XIX definían como "carácter" (Palmer, 1984, pp. 9-I I). En su ensayo, Rowe dejaba en evidencia cómo la crítica racionalista había expurgado este término de su vocabulario — desde Viollet-le-Duc en adelante- como parte de la revisión histórica que se desarrolla en el texto, estableciendo así que el carácter entrañaba la suficiencia expresiva que debía tener una obra para transmitir "la impresión de individualidad artística y la exteriorización, simbólica o funcional, de la finalidad a la que estaba destinado" (1980, p. 65).

A contrapelo de los enunciados teóricos, que por aquellos años se estaban forjando en Alemania, Kulczewski no quiso renegar de los principios comunicativos que habían singularizado a la arquitectura de los últimos siglos. Confiado en el poder de ésta como vehículo de comunicación cultural, Kulczewski parece haber empleado la idea de carácter asociada a la composición y el ornamento de las viviendas, las que no solo debían parecer tales, sino que además debían tener alguna cualidad que fuera distintiva o identitaria del conjunto de los grupos sociales a quienes iban dirigidas (Harris, 2018). 

a la de consenso social, porque actuaba como aglutinadora de diferencias y marcaba la existencia de grupos y colectivos con intereses comunes y deseos compartidos. El hacer del carácter una categoría de primer orden no era inocente, se garantizaba con ello que la arquitectura era precisamente lo que encarnaba esos valores de consenso en cristalizaciones construidas, en edificios representativos y parlantes. (Quesada, 2014, p. 6)

El lenguaje antiacadémico se expresó en Kulczewski a través del sincretismo formal que caracterizó su lenguaje decorativo. Tomando elementos tanto de la tradición historicista como de las vanguardias arquitectónicas, creó un imaginario propio a partir de yuxtaposiciones bizarras (Harris, 2018). La suma originalidad de esta práctica es la que les ha otorgado una distintividad indiscutible a estos conjuntos.

La práctica de Kulczewski de dirigir en terreno a los estuquistas en la realización de los ornamentos, que se proyectaban a escala natural directamente en la obra, tenía sus días contados (Harris, 2018). El trabajar en contacto inmediato con estos ejecutantes, promocionando el valor de las artes decorativas, era algo que llenaba de orgullo a Kulczewski. Como indican Torrent y Atria (20 I 5), este quehacer tenía también una raigambre ideológica, al estar asociado a las corrientes pioneras del socialismo decimonónico: "Muchas de sus aproximaciones estilísticas pudieron estar dominadas por un interés ideológico en la relación entre artesanado y producción arquitectónica, más cercana a las ideas de totalidad integrada [Gesamtkunstwerk] que a las del arte decorativo de la tradición francesa" (20।8, p. 38).

\section{MARCOS LESGISLATIVOS}

Intentar argumentar la razón por la que los conjuntos habitacionales de Kulczewski se constituyen como modélicos, en el contexto de la arquitectura chilena, es un asunto que debe ser confrontado desde diferentes ángulos. En un sentido deductivo, el análisis en torno a estas urbanizaciones permite reconocer la materialización de las políticas estatales que buscaban, desde comienzos del siglo pasado, incentivar la construcción de viviendas económicas por parte de agentes privados. En el caso de las intervenciones de Kulczewski, la mayoría de ellas fueron concretadas por cooperativas de trabajadores y empleados de las Fuerzas Armadas. Según afirma Burmeister (1969), sin aportar fechas, Kulczewski habría trabajado como arquitecto de la Dirección de Carabineros —ejemplo de esta labor fue la realización en 1925 del estadio de la policía de Santiago, hoy demolido-, a la vez que se desempeñó como arquitecto del Departamento de Bienestar de Ferrocarriles del Estado (Riquelme, 1996).

El escenario legislativo que dio inicio a las cooperativas de vivienda en Chile fue la Ley de Habitaciones Baratas de 1925, De- 
creto de Ley n. ${ }^{\circ}$ 308, que vino a reemplazar a su antecesora de 1906. Esta norma fue planteada por el Estado como una medida de fondo para resolver el déficit habitacional que había en el país, en el cual estas sociedades tenían un rol fundamental, como señala Hidalgo:

Las cooperativas de vivienda son por primera vez puestas en un sitial importante para resolver el déficit de residencias, el aporte que podían realizar las sociedades de empleados y trabajadores para solucionar su respectiva falta de habitaciones fue considerado como uno de los puntos fundamentales de la ley. (2005, p. 12I)

Bajo su jurisdicción se construyeron más de seis mil casas en todo el país. En el quehacer profesional de Kulczewski, esta ley le permitirá encausar sus preocupaciones sociales, materializando conjuntos residenciales económicos para diversas cajas y cooperativas, abordando excepcionalmente encargos privados. En la década inmediatamente posterior a la promulgación de la ley, construirá en total más de 300 casa baratas [Tabla I].

Una ciudad que para los años 20 llega a medio millón de habitantes requería sin lugar a dudas plantearse el problema de la vivienda, tanto desde la oportunidad de la inversión privada como desde la promoción pública. Este fue un ámbito profesional que Kulczewski capitalizó de manera excepcional, particularmente por la oportunidad que daba la nueva institucionalidad — la Ley de habitaciones baratas de 1925_- pero también seguramente porque era donde se realizaban sus ideales de una sociedad mejor. (Torrent y Atria, 2015, p. 28)

Nuevas políticas habitacionales formuladas en 1936 se cristalizarán en las obras que gestionará Kulczewski como administrador la Caja del Seguro Obrero Obligatorio, entre 1939 y 1940. Estas leyes fueron resultado del interés del Estado por modernizar la coordinación de los estamentos que podían organizar y dictar las bases técnicas de estas legislaciones habitacionales e, igualmente, generar soluciones concretas. De esta manera, se crea la Caja de Habitación Popular (Ley n. ${ }^{\circ}$ 5950), cuyo destino era trabajar mancomunadamente en los quehaceres descritos por la Caja del Seguro Obrero.

En el discurso ofrecido por Kulczewski como vocero del gobierno en el Primer Congreso Panamericano de la Vivienda Popular, celebrado en Buenos Aires en 1939, afirmaba:

Se gasta ingenio y tinta en buscar soluciones que van desde el material inverosímil hasta planimetrías absurdas, como nichos de cementerios; o se buscan terrenos que, por su precio, lin- 


\section{CIUDAD MODERNA E INCLUSIÓN}

\begin{abstract}
den a páramos o basurales en los extramuros de las ciudades, creando a sus viviendas, nuevas y crueles diferencias. Se forman barriadas de casas baratas, que evidencian más el contraste entre los felices y los infortunados, enrostrando una vez más a estos últimos su mísera condición. [...] El Gobierno de Chile, la Caja de Seguro Obrero, consideran que la política de la vivienda debe ser dar habitación higiénica, confortable y bella, que tienda a reconstruir el hogar, la familia proletaria, y con ello recuperar para la sociedad, justa y armónicamente organizada. (citado por Anónimo, 1939, pp. 199/93-200/94)
\end{abstract}

Es importante resaltar que la introducción en el discurso del término "higiene" refleja la forma en que las políticas estatales se habían visto impactadas por los procesos modernizadores asociados a la construcción de viviendas (Aguirre, 20 I I, p. 58). De igual forma, con el tiempo, conceptos como el de "belleza" serían excluidos del vocabulario racionalista.

Se desprende también de las citadas palabras del arquitecto que, en lo concerniente a la situación urbana, el emplazamiento de estos conjuntos debía materializarse en solares céntricos, para así evitar la segregación. Este aspecto no hacía más que reflejar las posturas estatales de la época, como se deduce de las propias opiniones del presidente de la época, Pedro Aguirre Cerda, que figuran en su discurso sobre política habitacional:

\footnotetext{
En mi concepto, el empleado y el obrero deben vivir en el interior de las ciudades, en forma que tengan todos los beneficios civilizadores de las escuelas y bibliotecas, de la luz, agua potable, alcantarillado, transportes, etc., de manera que la clase trabajadora se sienta como un componente social tan digno y respetable como lo es todo ciudadano forjador de la riqueza pública. (citado por Galaz-Mandakovic, 20। I, p. 59)
}

De una suerte semejante, los conjuntos habitacionales de Kulczewski irán ilustrando el modo en que se fue expandiendo la metrópolis moderna. Para el caso particular de Santiago de Chile, mientras que conjuntos como los del Barrio Yungay [Figura I] y de la calle Madrid dan cuenta de las incursiones del arquitecto en el centro histórico (González, 2019; Fuentes, 2009), con posterioridad a 1926 comenzará a levantar grupos habitacionales en las nuevas comunas que nacerán en la periferia, particularmente Providencia y Ñuñoa, vinculadas al concepto de "ciudad jardín" [Figura 2]. Palmer discute esta problemática en su monografía sobre el asunto, al afirmar que las realizaciones de Kulczewski se encuentran entre las primeras poblaciones articuladas a partir de esta incipiente noción de barrio (1986, p. 7I). 
Figura 1

Axonometría de los conjuntos del Barrio Yungay. 1. Viviendas calle santo Domingo, 2. Viviendas calle Esperanza, 3. Cité

Esperanza y 4 .

Viviendas calle

Santo Domingo.

Fuente: realización

Javier Vargas

Martínez.

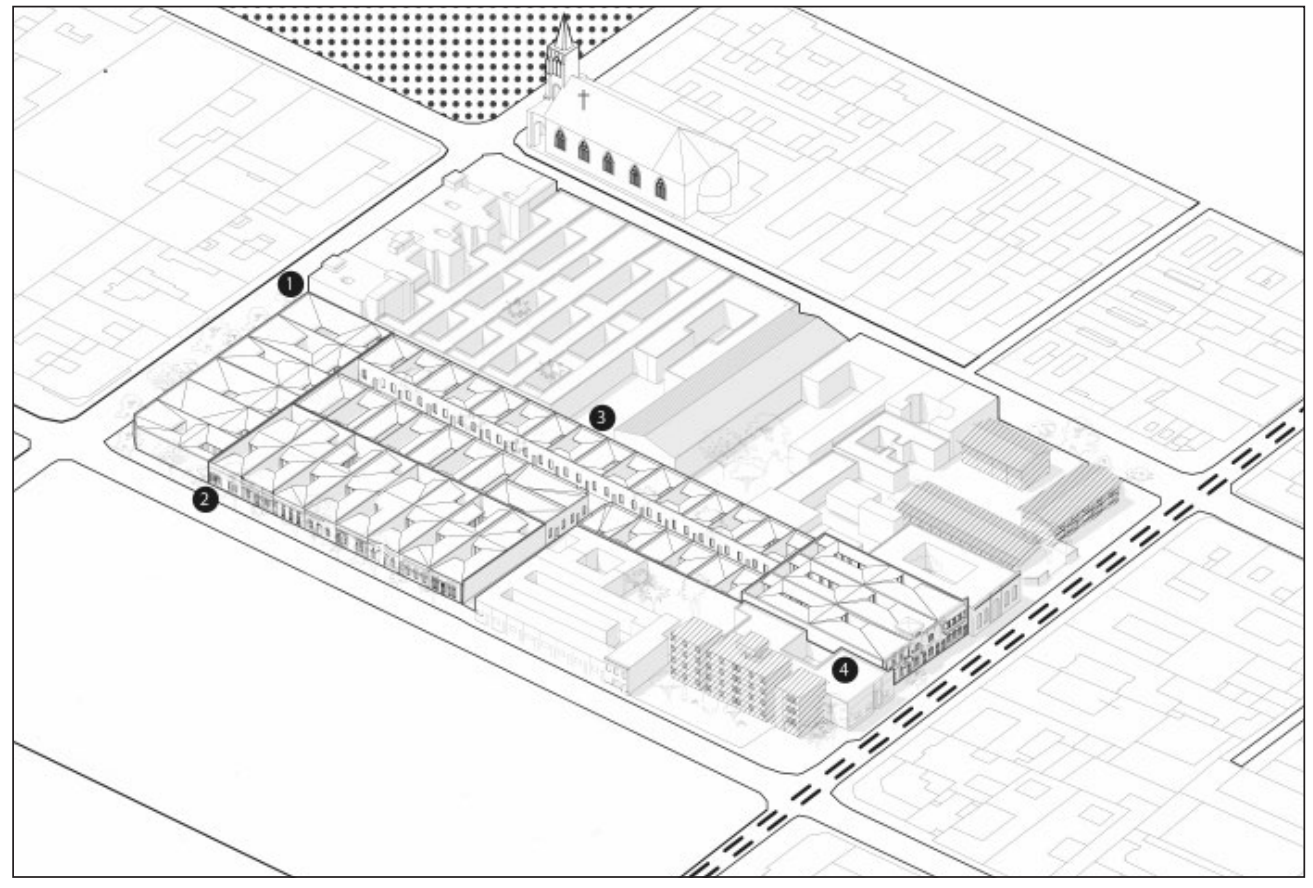

Figura 2

Población

Comunidad Keller,

vereda norte.

Fuente: Archivo

Kulczewski, Archivo

Chilena, Universidad

de Chile.

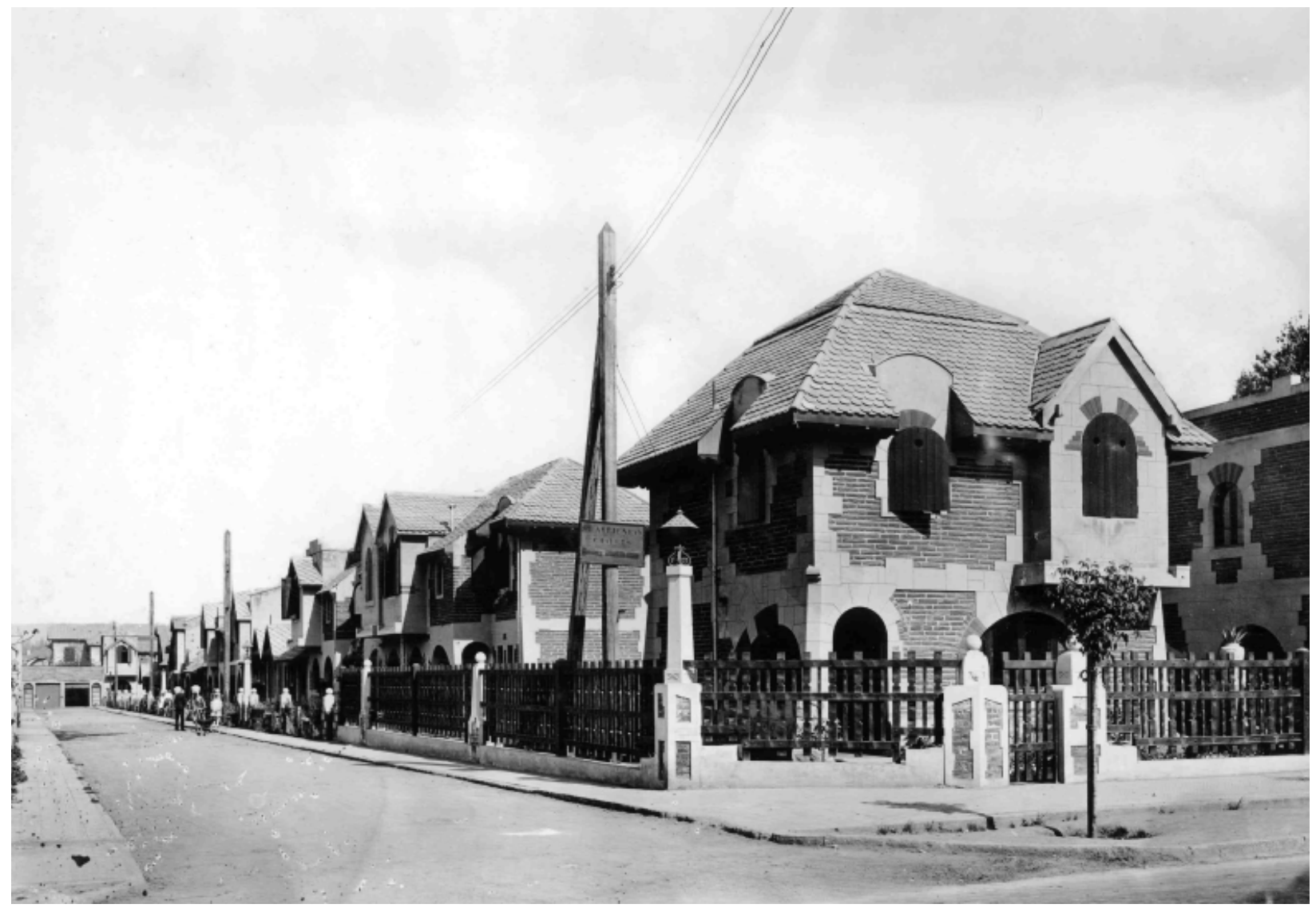


Figura 3

Población Caja plano de conjunto.

Fuente: Plano del

Archivo Técnico Pacheco Aravena. Nacional de Ahorros

de Aguas Andinas,

intervenido por Raúl

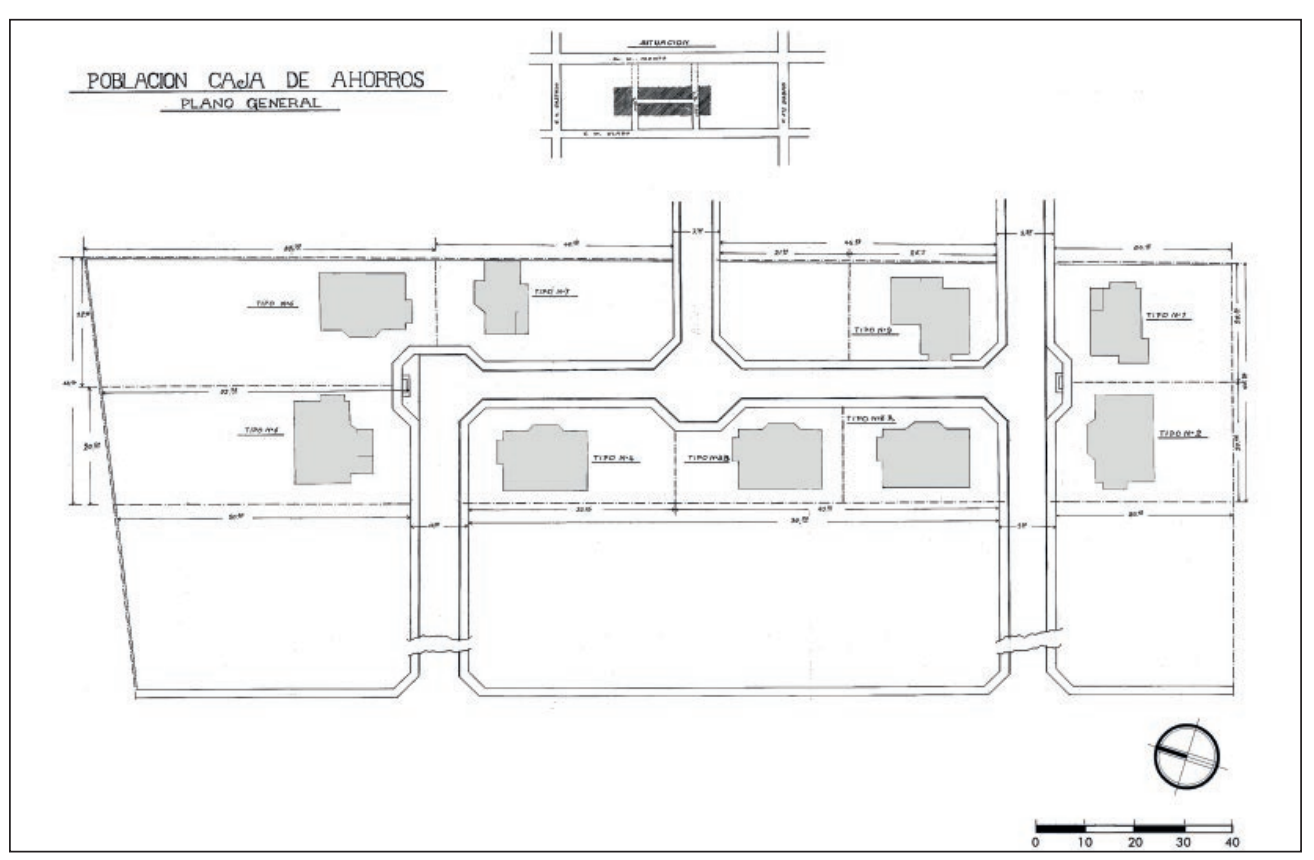

Intervenir en contextos tan diversos obligará al arquitecto, por

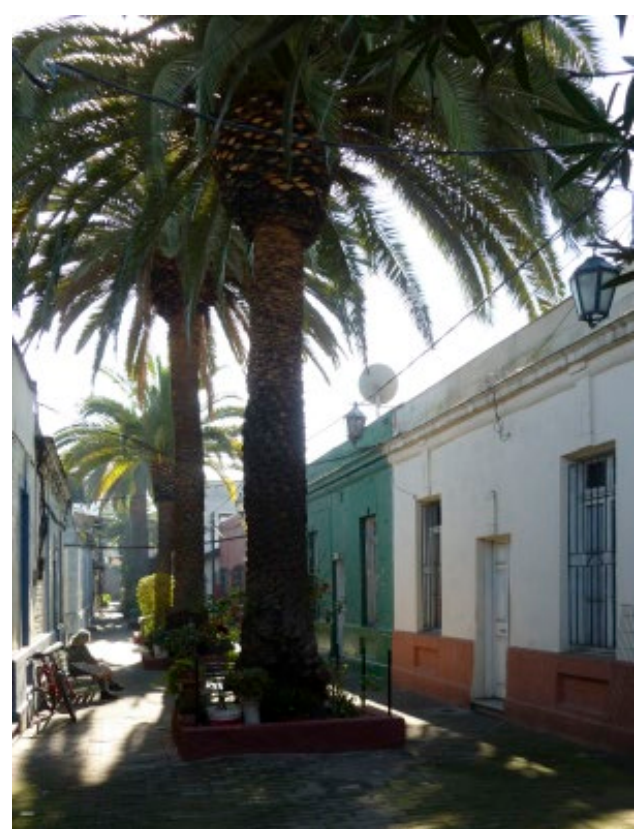
una parte, a pluralizar sus estrategias de agenciamiento urbano $y$, por otra, a verse asociado a un planteamiento innovador de la vivienda. Si en la ciudad histórica empleó la casa tradicional de edificación continua, resuelta en solares entre medianeras y organizada en torno a patios interiores, en las urbanizaciones posteriores optó por el modelo de casa pabellón, que se adaptaría mejor a los amplios solares ajardinados [Figuras 3 y 7]. Este proceso se fue dando gradualmente, como lo corrobora la población para suboficiales de la Escuela de Aplicación de Caballería y la población Keller [Figura 2], levantadas en las comunas del sector oriente ya mencionadas. En estos casos, si bien los conjuntos fueron llevados a cabo bajo los principios de la ciudad jardín, y cada residencia cuenta con antejardín y patio posterior, las construcciones no abandonan el esquema de casa pareada, configurando bloques de edificación continua.

Persiguiendo siempre enfatizar la idea de unidad, Kulczewski opta por un tipo de operación urbana consistente en crear pequeños conjuntos, dispuestos a partir de calles y pasajes menores insertos dentro de grandes manzanas. Mientras que en las intervenciones realizadas en el centro histórico el arquitecto adoptará en ocasiones el concepto de "cité" - un conjunto de viviendas, generalmente de fachada continua, que enfrentan un espacio privado de uso común que se conecta con una calle principal por medio de uno o varios accesos [Figura 4]-, en los barrios jardín las organizará respondiendo al trazado dibujado por discretas vías interiores. Esta peculiaridad, aparentemente transversal a todas sus realizaciones, convertirá a sus conjuntos en "pequeños microcosmos" ${ }^{4}$, con un cierto grado de autonomía espacial respecto a su contexto [Figura 5].
4 Para una revisión crítica de este término, ciudad, un argumento similar se estila en Kostof (1991). consultar Eliade (1988); y en relación con la 
Figura 5

Análisis

comparativo de

las estructuras

viales de algunos

conjuntos
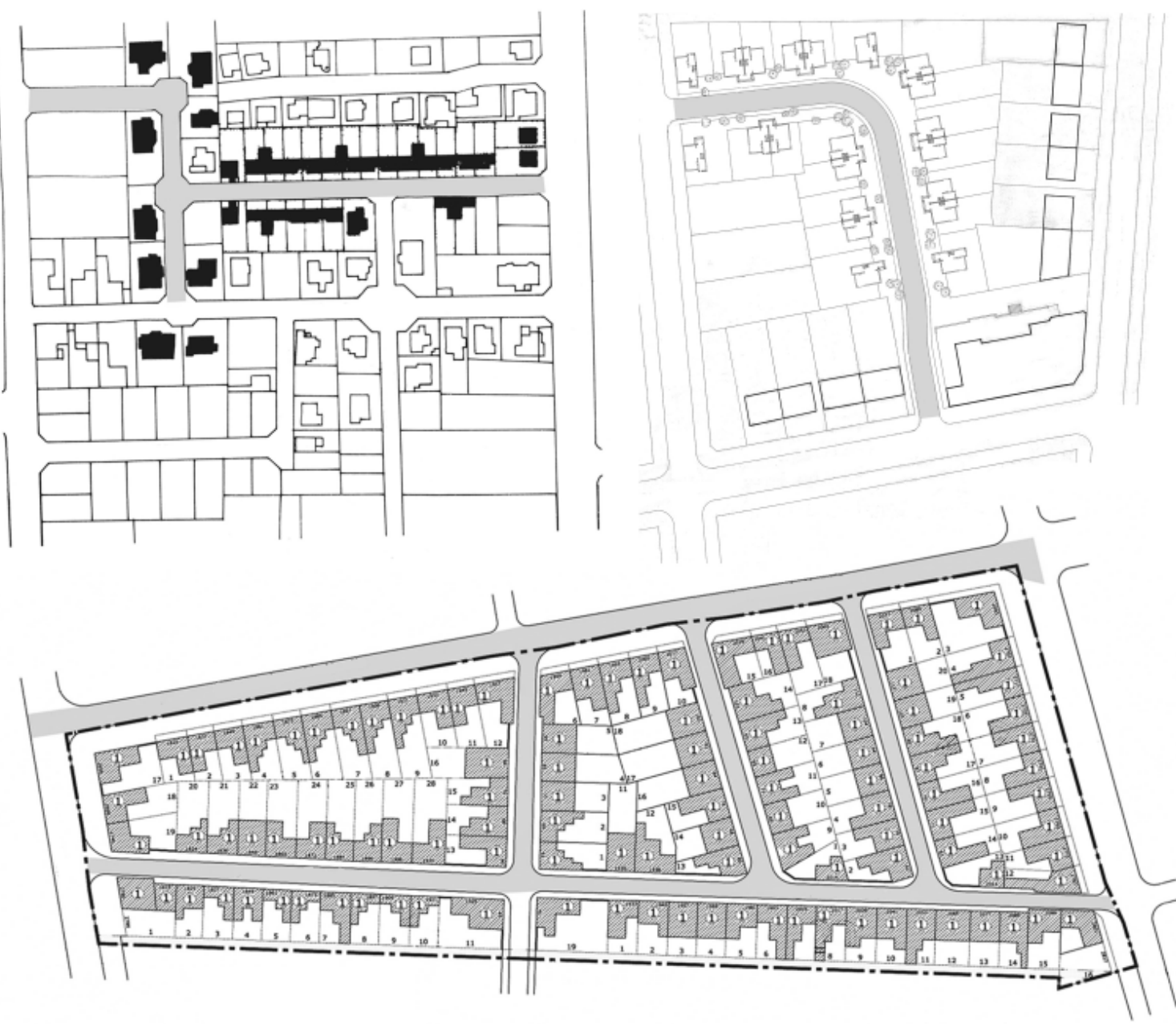

habitacionales

diseñados por

Kulzcewski.

Keller y Caja

Keller y Caja

acional de

Ahorros, 2 .

Población de

Puboficiales,

: Conjunto calle

Pintor Cicarelli

4. Conjunto

Virginia Opazo y

5. Conjunto de

viviendas de

Vitacura.

Fuente: Planos

de los Archivos

Técnicos

Dirección de

obras Municipales

correspondientes,

correspondien

por Raúl Pacheco

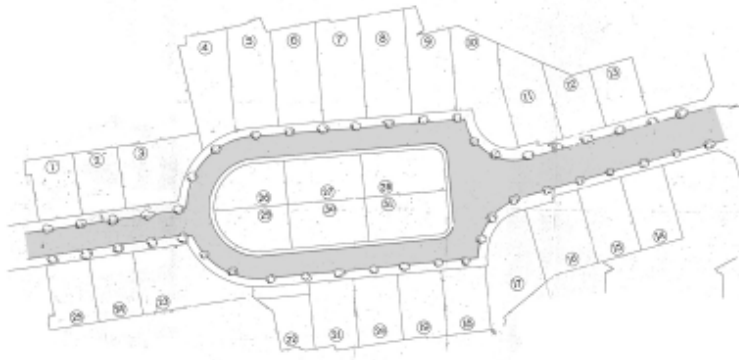

Aravena.

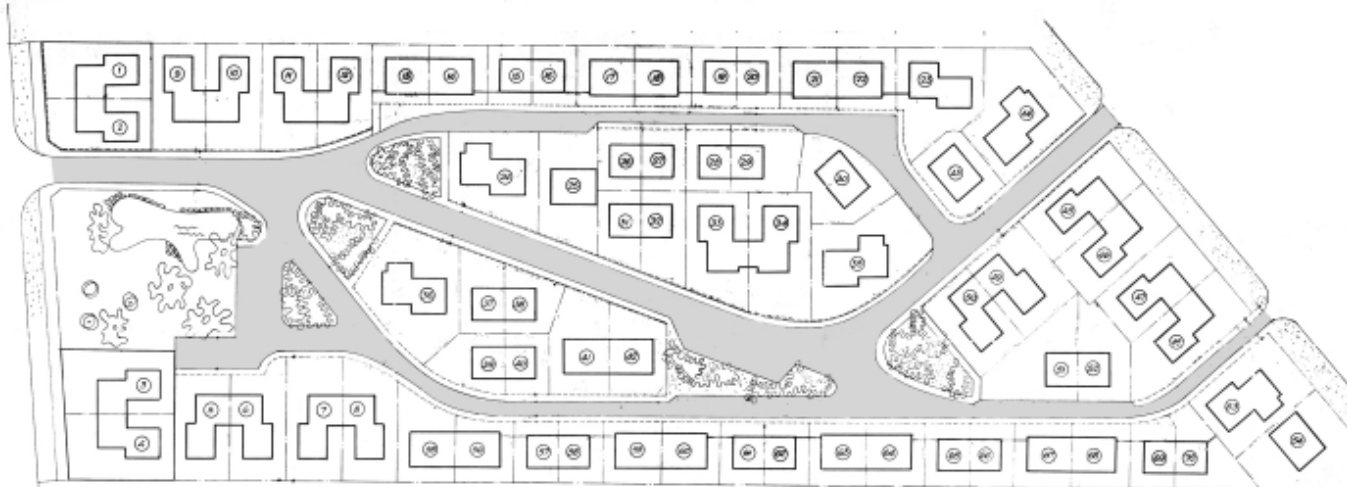


Figura 6

Población Caja

Nacional de Ahorro,

axonometrías de las

viviendas: tipo

Decombe 1154),

tipo C (calle' Luis

Barros Valdés 788),

tipo B (calle

Alberto Decombe

$1155)$. Fuente:

realizadas por

Carla Vega Osorio.
El proyecto de viviendas fue central en su actividad como arquitecto, y lo fue en tanto configuradora de ciudad. [...] La clave estaba en la definición del conjunto por medio del trazado a fin de lograr un máximo aprovechamiento del solar, pero con una mayor definición del diseño por medio de las grandes líneas de la forma urbana. (Torrent y Atria, 2015, p. 34)

Este tipo de trazados son abiertamente deudores de los principios artísticos propuestos por Camillo Sitte, ya que Kulczewski buscaba crear lugares pregnantes y acotados que favorecieran la integración o inclusión de sus residentes. Desde esta perspectiva, a su estrategia de concebir formas urbanas reconocibles, favorecidas por un trazado de hileras de viviendas claramente definidos, se añadía el manejo de umbrales de acceso que permitían a sus residentes tomar conciencia de cuándo se encontraban accediendo o abandonando dicho lugar.

Dado que la idea de calle, como elemento organizador, quedaba configurada por medio de la alineación de las viviendas, en aquellos otros, concebidos a modo de un townscape, los accesos se manifestaban mediante el adelanto o retranque de las viviendas que se emplazaban en las esquinas de las vías de entrada. Distintas estrategias en la creación de umbrales se pueden apreciar en la comunidad de calle Keller, la más conseguida en este aspecto, donde grandes luminarias se erigían en las arterias de acceso, que, a modo de faros, guiaban a sus habitantes [Figura 2]. Otra solución, como se reconoce en el conjunto población Caja Nacional de Ahorros, es el tratamiento dado a los encuentros de las calles, cuyas esquinas están ochavadas y las que en su conjunto configuran un ensanche
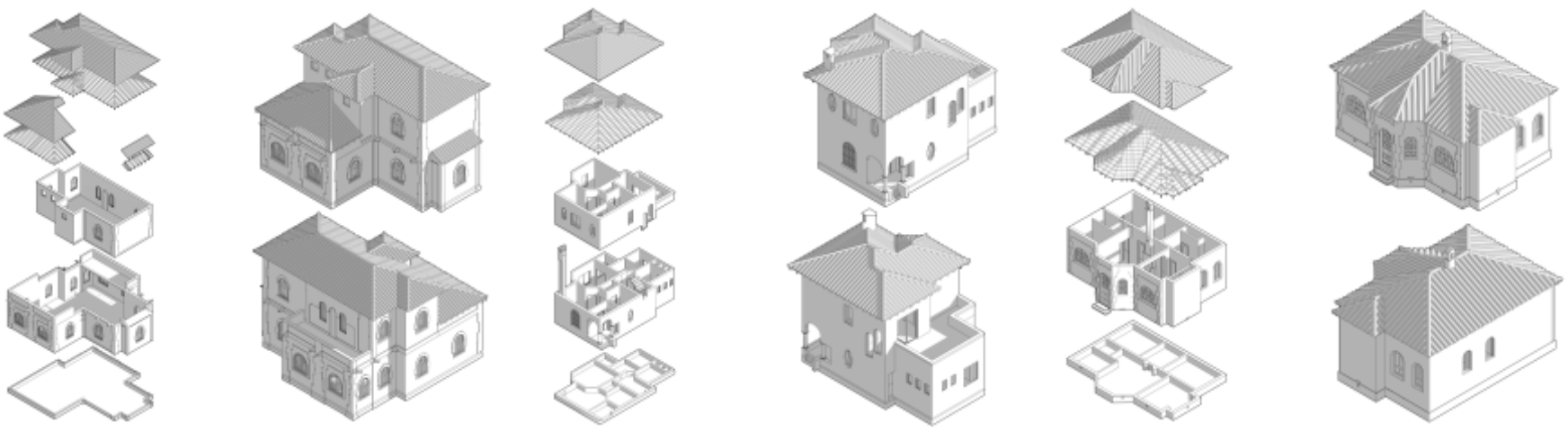
Figura 7

Población Caja

Nacional de Ahorro,

sección por calle

General Córdova.

Fuente: realizado

por Carla Vega

Osorio. octogonal [Figura 3], obteniendo, de esta manera, que "el ingreso o la salida al barrio y a cada una de sus calles [sea] a través de una figura que marca una especie de descompresión, como el zaguán en las antiguas casas" (Palmer, 1984, p. 7I).

Otro aspecto que es necesario hacer notar es el manejo de la escala de las viviendas, que logran transmitir hacia el espacio público común un carácter de íntimo recogimiento. La arquitectura entendida como lugar de protección cobra fuerza al apreciar estos conjuntos, entendiendo que, con su diseño, Kulczewski estaba configurando el hábitat moderno, el lugar de cobijo y bienestar para las familias trabajadoras, las que corresponden al núcleo del nuevo proyecto de nación que sus contemporáneos enarbolaban con el despuntar del siglo.

Un aspecto mencionado, que es oportuno destacar al momento de recapitular, es la manera en que, haciendo eco de los principios fundacionales que venían asociados con la modernidad arquitectónica, Kulczweski empleaba en sus realizaciones un número determinado de viviendas-tipo cuyas variantes estaban definidas, a su vez, por la configuración de sus espacios interiores [Figuras 6 y 7]. Esta operación tenía un alcance mayor que el puramente formal -a saber, ofrecer una variedad morfológica que evitaba la monotonía plástica inherente al diseño de poblaciones-, ya que el elemento determinante de esta diversidad guardaba relación con los diferentes metrajes de las viviendas, permitiendo la inclusión de compradores de diferentes estratos económicos en un mismo conjunto.Y aun cuando los orígenes de algunas de estas poblaciones estaban vinculados al mundo castrense o policial, en estas últimas, al menos, Kulczewski procuró dar cabida, en un mismo conjunto, a los distintos miembros del escalafón institucional gracias al empleo de diferentes tipologías.

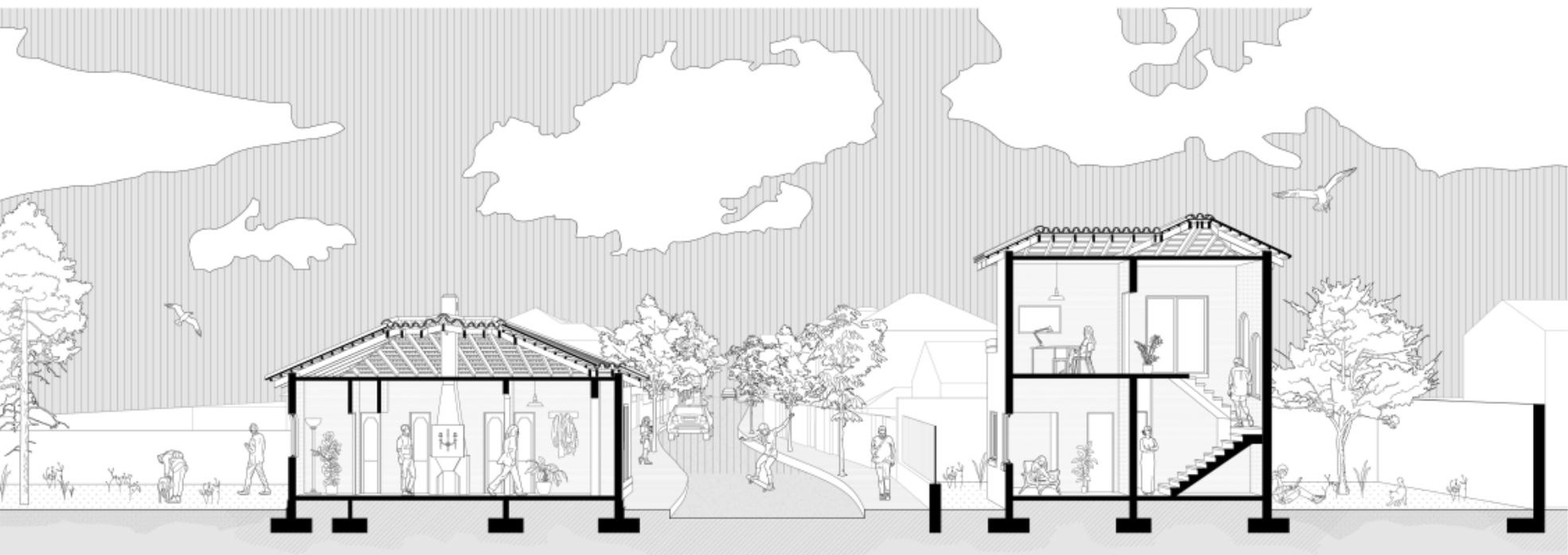


Figura 8

Axonometría de Poblaciones

Comunidad Keller y

Caja Nacional de
Ahorros. Fuente:

realizada por Carla

Vega Osorio.
Muchas de las estrategias que permitían discriminar los diversos tipos de vivienda, a nivel ornamental, se conectan también con aspectos económicos. Por tratarse de casas baratas en la mayoría de los casos, la economía de recursos solo permitía variaciones en los ritmos y soluciones estructurales de los vanos (adintelados o conforme distintos tipos de arcos) [Figura 6] y en los elementos decorativos en estuco, dispuestos sobre muros y falsos hastiales. Las variaciones morfológicas se limitaban a los tipos, generalmente acotados, y siempre en viviendas de hasta dos pisos [Figura 2]. Será únicamente en algunos conjuntos posteriores, dirigidos a una clase media acomodada, como el conjunto de viviendas de la comuna de Vitacura y la población Caja Nacional de Ahorros, que Kulczewski pudo permitirse el lujo de jugar con un mayor número de mutaciones. De hecho, es en esta última donde, a priori, se contaba con información sobre los propietarios, por lo que, al adecuar las soluciones a las variadas necesidades de estos, los volúmenes de las casas resultaron necesariamente heterogéneos [Figuras 3, 6 y 8].

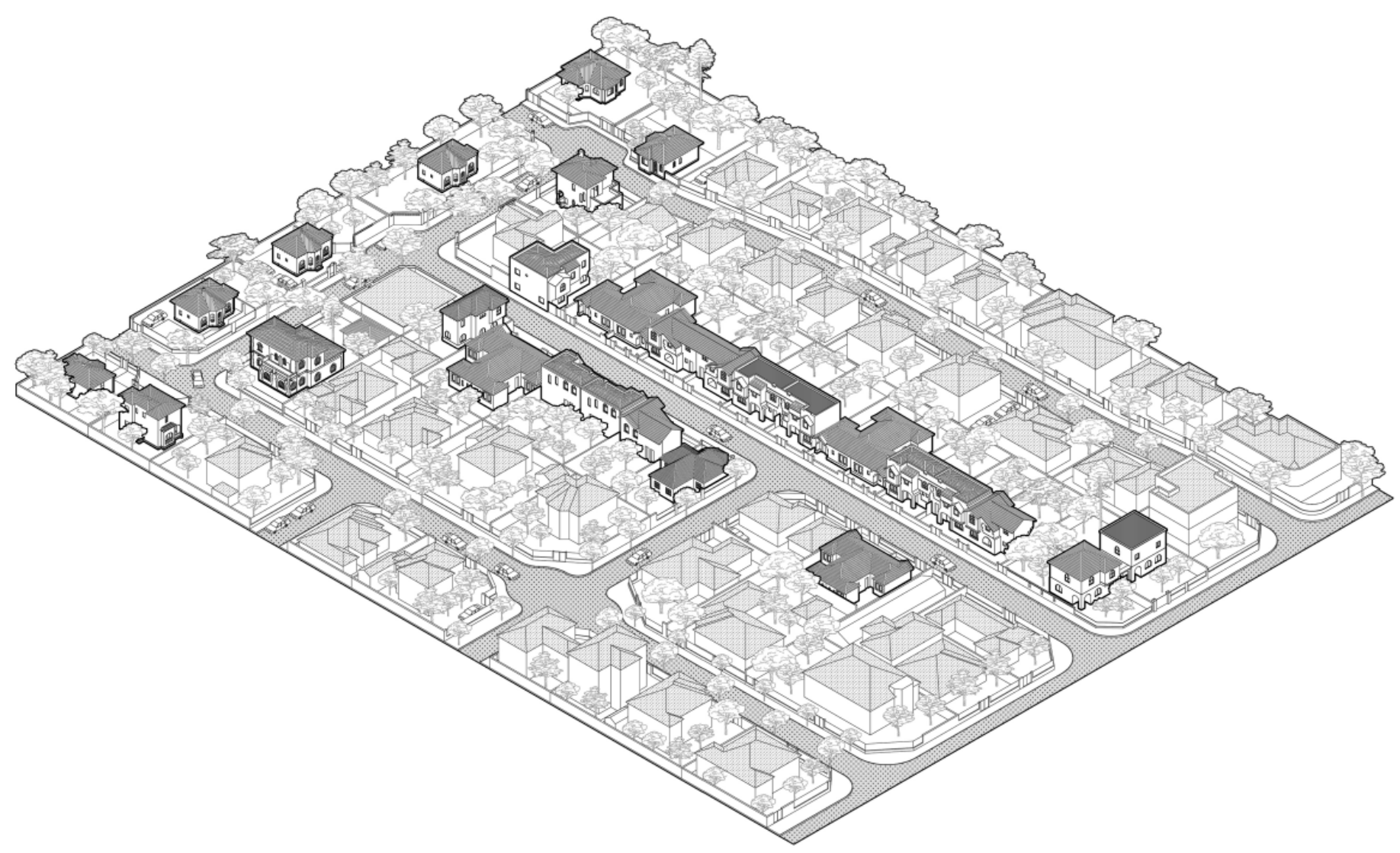




\section{COMENTARIOS FINALES}

Con el advenimiento de posmodernidad, uno de los aspectos que se ha puesto en cuestión es la definición tradicional de lo que entendemos por "lugar". Ello se ha concretado tanto en la crítica que se ejerció hacia algunas de las propuestas del Movimiento Moderno, como en la actual problemática planteada por la espacialidad virtual, "la crisis de lugaridad". En este insatisfactorio contexto, no deja de llamar la atención que existan comunidades que, con orgullo, exterioricen las bondades de los lugares que habitan, convirtiendo de paso a Kulczewski en el arquitecto más mediático del medio nacional.

Lo argumentado en este artículo queda refrendado por el actuar de los residentes de los conjuntos analizados, quienes han sabido reconocer los valores urbanos y arquitectónicos de sus propias viviendas, organizándose para lograr la categoría de Zonas Típicas o Pintorescas, designación patrimonial otorgada por el Estado con el fin de proteger poblaciones o conjuntos habitacionales que sean representativos de la evolución de la comunidad humana y que destacan por su unidad estilística, materialidad o técnicas constructivas. Señala Pérez de Arce al respecto: "en estos espacios Kulczewski logra una acogida que pocos arquitectos han tenido en nuestro medio. Al menos desde el espacio de la calle, éstos aparecen como lugares dignamente preservados, evidenciando una afectividad real" (1997, p. 78). Tal distinción, si bien ha permitido conservar estos conjuntos, no permite proteger del todo el carácter ambiental del entorno inmediato. De allí que el rasgo común que caracteriza a las organizaciones de vecinos es la de empoderarse para enfrentar la amenaza que significa el avance del "capital inmobiliario en sus territorios, expresado en la edificación en altura" (Olguín, 20 I8, p. 27). Las sombras de enormes torres de departamentos se suelen proyectar sobre estos barrios, no solo desfigurando la apreciación del paisaje urbano, sino también sintomatizando el aumento de densidad habitacional que amenaza seriamente la escala íntima de los conjuntos.

Como propone el DoCoMoMo Chile, en la voz de Horacio Torrent, es necesario que el reconocimiento popular de los valores patrimoniales tenga cabida en los organismos que proponen las leyes de protección estatal, y privados eventualmente. Lo anterior, todavía más si se tiene en cuenta la actual discusión que la Comisión de Cultura de la Cámara de Diputados de Chile sostiene para modificar la Ley 17.288 de monumentos nacionales de 1970:

La solicitud [de conservación histórica] viene siempre acompañada de una condición reivindicativa, que asigna valores históricos, sociales e incluso económicos a esos conjuntos o sectores urbanos, como defensa ante la amenaza de la expectativa rentable. Se trata, básicamente, del reconocimiento que la población hace de una condición 
material, porque porta sus memorias de comunidad, pero más que eso, porque importa una serie de significados asociados a la forma de vida cotidiana que no quiere perder. $(20 \mid 8$, p. II)

Contrariamente a la lógica que dispone el discurso científico al uso, el origen de esta investigación se convierte en una decidora argumentación al momento de concluir. En una charla sobre Kulczewski, realizada por Fernando Riquelme el día 27 de mayo de 2012 en el Centro Cultural Gabriela Mistral (GAM), con ocasión del Día del Patrimonio, Paulina Uribe Campos, residente y principal promotora del resguardo de la población para Suboficiales de la Escuela de Aplicación de Caballería - acción que culminó en mayo de 2007 con la declaratoria de Zona Típica o Pintoresca-, pidió la palabra para comentar el privilegio que significaba para ella vivir en un conjunto diseñado por el arquitecto. Dicha valoración radicaba en el hecho de que, aunque dicho conjunto estaba conformado por viviendas económicas, Kulczewski había sabido dotarlas de un sentido de belleza vinculado al "estilo y la estética de la época". Esta prerrogativa de realizar casas "a la moda", era algo que, según ella, en aquellos años solo estaba reservado para las residencias de clase alta. Debido a su certeza incuestionable, este testimonio se vuelve clarificador en torno al horizonte analítico con que se han querido tratar estas obras.

AFACAN, Y. Y AFACAN S. (2011). Rethinking social inclusivity: design strategies for cities. Urban Design and Planning, 164(2), 93-105. DOI: 10.1680/ udap.2011.164.2.93

AGUIRRE, M. (2011). La arquitectura moderna en Chile (1907-1942). Revistas de Arquitectura y estrategia gremial. Santiago de Chile: Editorial Universitaria.

ANÓNIMO (1939). Primer Congreso Panamericano de la Vivienda Popular celebrado en Buenos Aires. Urbanismo y arquitectura (5), 198/92-204/98.

BURMEISTER, E. (1969). Aportes individuales al desarrollo de la arquitectura chilena: la obra del arquitecto Luciano Kulczewski (Seminario de investigación de pregrado). Universidad de Chile, Santiago de Chile.

DUK, C. Y MURILLO, J. (2016). La Inclusión como Dilema. Revista latinoamericana de educación inclusiva, 10(1), 11-14. DOI: https://dx.doi. org/10.4067/S0718-73782016000100001 
ELIADE, M. (1988). Lo sagrado y lo profano. Barcelona: Editorial Labor.

FUENTES, P. (2009). Antecedentes de la Arquitectura Moderna en Chile 1894 - 1929. Concepción: Ediciones Universidad del Bío-Bío.

GALAZ-MANDAKOVIC, D. (2011). Edificios Colectivos de la Caja del Seguro Obrero Obligatorio de Tocopilla 1939-41. Movimiento Moderno, solución social. Tocopilla, Chile: Retruecanosinversos.

GONZÁLEZ, K. (2019). Lineamientos de intervención para Zona Típica Población Madrid (Seminario de postgrado, Postítulo en conservación y restauración arquitectónica). Santiago de Chile: Universidad de Chile.

HARRIS, R. (2020). La moderna gestión de Luciano Kulczewski. Los casos de los Edificios Colectivos para Obreros de Arica e lquique. AUS [Arquitectura/Urbanismo/Sustentabilidad] (27), 12-17. DOI:10.4206/aus.2020.n27-03

HARRIS, R. (2018). Contaminaciones estilísticas en la obra de Luciano Kulczewski. Yuxtaposición de imaginarios como estrategia de apropiación. Revista 180 (41), 44-53. DOI: http://dx.doi.org/10.32995/rev180.Num-41. (2018).art-397

HARRIS, R. (2016). Caracterización mediática del corpus productivo de Luciano Kulczewski. En P. Corro y C. Robles (Eds.), Estética, medios masivos y subjetividades (pp. 185-193). Santiago: Instituto de Estética, Pontificia Universidad Católica de Chile.

HIDALGO, R. (2005). La vivienda social en Chile y la construcción del espacio urbano en el Santiago del siglo XX. Santiago de Chile: Instituto de Geografía de la Pontificia Universidad Católica de Chile, Centro de Investigaciones Diego Barros Arana.

KOSTOF, S. (1991). The city shaped. Urban patterns and meanings through history. Hong Kong: Bulfinch Press.

OLGUín, R. (2018). El capital social como insumo movilizador en torno al patrimonio habitacional moderno: los casos de Villa Olímpica en Ñuñoa y Remodelación San Borja en Santiago centro. DU\&P Revista de Diseño Urbano y Paisaje (33), 26-33.

MÉNDEZ, M. Y BAZORET, E. (2012). Lo auténtico también es público. Comprensión de lo público desde las clases medias en Chile. Polis (Santiago), 11(31), 183-202. DOI: https://dx.doi.org/10.4067/S071865682012000100011

PALMER, M. (1984). La comuna de Providencia y la Ciudad Jardín. Un estudio de los inicios del modelo de crecimiento actual de la ciudad de Santiago. Santiago de Chile: Facultad de Arquitectura y Bellas Artes, Pontificia Universidad Católica de Chile.

PALMER, M. (1987). La Ciudad Jardín como modelo de crecimiento urbano. Santiago 1935- 1960. Santiago de Chile: Facultad de Arquitectura y Bellas Artes, Pontificia Universidad Católica de Chile.

PÉREZ DE ARCE, R. (1997). Reseña de La Arquitectura de Luciano Kulczewski. ARQ (35), 77-78.

QUESADA, F. (2014). Arquitecturas parlantes. Edificios con carácter. Circo M. R. T. (195), 1-15. Recuperado de https://www.academia.edu/24903591/

RIQUELME, F. (1996). La Arquitectura de Luciano Kulczewski. Un ensayo entre el eclecticismo y el Movimiento Moderno en Chile. Santiago de Chile: Ediciones ARQ.

ROWE, C. (1980). Manierismo y arquitectura moderna y otros ensayos. Barcelona: Gustavo Gili.

TORRENT, H. Y ATRIA, M. (2015). Luciano Kulcewski, arquitectura para la ciudad en transformación. Revista AOA (30), 16-39.

TORRENT, H. (2018). Patrimonio moderno y sustentabilidad. En H. Torrent et al. (Eds.), Patrimonio moderno y sustentabilidad: de la ciudad al territorio (pp. 1014). Santiago de Chile: Docomomo Chile. 